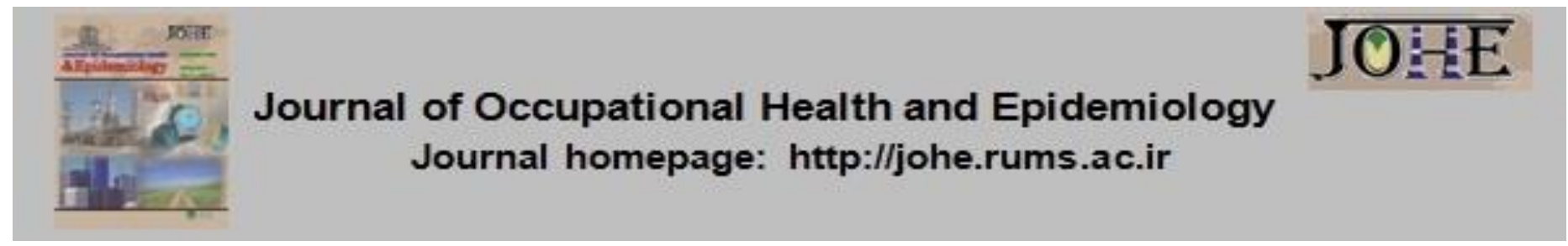

\title{
Pediatric Cutaneous Leishmaniasis in Hormozgan Province, Southeast Iran during 2016-2020: A Descriptive Epidemiological Study
}

\author{
Sajjad Fekrijaski ${ }^{1}$, Mehdi Zare ${ }^{2}$, Moussa Soleimani-Ahmadi ${ }^{*}$, Kaveh Soleimani ${ }^{4}$, Alireza Sanei- \\ Dehkordi ${ }^{5}$
}

1. MSc in Microbiology, Infectious and Tropical Diseases Research Center, Hormozgan Health Institute, Hormozgan University of Medical Sciences, Bandar Abbas, Iran.

2. Associate Prof, Dept. of Occupational Health Engineering, Faculty of Health, Hormozgan University of Medical Sciences, Bandar Abbas, Iran.

3. Professor, Dept. of Medical Entomology and Vector Control, Faculty of Health, Hormozgan University of Medical Sciences, Bandar Abbas, Iran; Social Determinants in Health Promotion Research Center, Hormozgan University of Medical Sciences, Bandar Abbas, Iran.

4. MSc in Parasitology, Infectious Disease Prevention and Control Unit. Hormozgan Province Health Center, Health Deputy of Hormozgan University of Medical Sciences, Bandar Abbas, Iran.

5. Associate Prof, Dept. of Medical Entomology and Vector Control, Faculty of Health, Hormozgan University of Medical Sciences, Bandar Abbas, Iran.

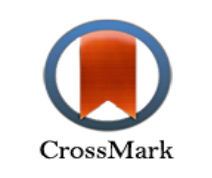

Citation: Fekrijaski S, Zare M, Soleimani-Ahmadi M, Soleimani K, Sanei-Dehkordi A. Pediatric Cutaneous Leishmaniasis in Hormozgan Province, Southeast Iran during 20162020: A Descriptive Epidemiological Study. J Occu Health Epidemiol 2021; 10(4):224-30.

\section{Article Info}

* Corresponding author:

Moussa Soleimani-Ahmadi,

E-mail:

mussa.sahmadi@gmail.com

\section{Article history}

Received: Oct 2021

Accepted: Nov 2021

$10.52547 /$ johe.10.4.224

Print ISSN: 2251-8096 Online ISSN: 2252-0902

Peer review under responsibility of Journal of Occupational Health and Epidemiology

\section{Abstract}

Background: Cutaneous leishmaniasis is an important infectious disease that affects all age groups, especially children, in endemic areas. This study aimed to investigate epidemiological aspects of pediatric (children under 15 years old) cutaneous leishmaniasis (PCL) in Hormozgan province, southeast Iran.

Materials and Methods: This descriptive study was conducted from 2010 to 2020. In this study, data were obtained from two databases, including the disease surveillance system of the Hormozgan University of Medical Sciences and epidemiological registration forms completed by leishmania focal points in the regional health centers. Data were analyzed using descriptive statistics, chi-square, and t-test using SPSS ver.21 software.

Results: In total, 394 confirmed cases of PCL were recorded. The PCL incidence rate was found to decrease from $10.37 / 100000$ cases in 2016 to $7.85 / 100000$ in 2020 . The mean age of the patients was $5.2 \pm 3.8$ years, and most of the cases $(239 / 394 ; 60.7 \%)$ belonged to the 0 to 5 -year-old group. The mean number of lesions was 1.5 per person, and most of the lesions were observed on the face followed by hands. Compared to females, the infection rate was higher in males, and 264 of the cases $(67 \%)$ were observed in rural areas. The higher incidence of PCL was observed in winter and fall with $183(46.5 \%)$ and $78(19.8 \%)$ cases, respectively.

Conclusion: our findings confirm that pediatric cutaneous leishmaniasis is an endemic disease in Hormozgan province, with more prevalent in children. Appropriate educational interventions for prevention along with active surveillance for rapid detection and treatment of the patients should be considered to reduce the prevalence of PCL in this province.

Keywords: Cutaneous Leishmaniasis, Epidemiology, Iran.

\section{Introduction}

Leishmania genus as a protozoan parasite is the cause of leishmaniasis in human communities.
This infection is demonstrated in three forms, including visceral leishmaniasis (VL), cutaneous 
leishmaniasis (CL), and mucocutaneous leishmaniasis (MCL) [1].

The $\mathrm{CL}$ is considered an important mosquito-borne disease caused by several Leishmania spp and transmitted by phlebotomine sand flies [2].

It is prevalent in the subtropical and tropical regions in 100 countries in Africa, America, Asia, and Europe [3]. The global new cases and deaths due to leishmaniasis have been reported to be about 2000000 and 20,000-40,000 per year, respectively [3]. According to the WHO report, more than two-thirds of new $\mathrm{CL}$ cases were reported from Afghanistan, Algeria, Bolivia, Brazil, Colombia, Iran, Iraq, Pakistan, Peru, Syria, and Tunisia [4]. According to many studies, children are at greater risk than adults, and most CL cases occur in this age group $[5,6,7]$. In this regard, different studies have considered the epidemiological aspects, therapeutic modalities, and clinical outcomes of $\mathrm{CL}$ in children in various parts of the world where CL is endemic. Most of these studies have been conducted in the age group of $0-14$ years $[6,8,9]$.

The $C L$ is one of the main health challenges in Iran, being recorded in 25 of 31 provinces of the country [10]. Annually, 22,000 cases of CL occur in Iran, and approximately $80 \%$ of CL patients have zoonotic cutaneous leishmaniasis (ZCL) [11]. The $\mathrm{CL}$ prevalence has been reported to be $1.8 \%$ $37.9 \%$ in different provinces of Iran [12]. The ZCL and anthroponotic cutaneous leishmaniasis (ACL) are two epidemiological forms of $\mathrm{CL}$ in Iran. The former caused by L.major is endemic in 21 out of 31 provinces [13]. IT is mostly endemic in arid rural regions, where the reservoir hosts exist $[14,15]$.

In recent decades, a noticeable increase in leishmaniasis cases has been observed in many parts of the world [16]. This increase may be the result of behavioral and environmental changes, including migration of people from rural to urban areas, unplanned urbanization, deforestation, dam building, and new irrigation projects, which increase human-sand fly contact [17, 18]. Accordingly, it is essential to identify active ZCL foci to establish effective control measures to prevent its spread to new areas.

The ZCL is considered a prevalent disease in the Hormozgan province. A previous study in this province has shown that patients under 20 years old represent $79.24 \%$ of the total infected population, with the highest percentage $(25.89 \%)$ occurring in the $6 \pm 10$ years age group [19]. The incidence rate of the disease in the province has been reported to be 22 per 100, 000 during the last 3 decades. This rate has decreased to 6.39 per100, 000 in recent years; however, the province is still considered the most critical endemic focus of ZCL in southeastern areas of Iran [Hanafi-Bojd 20]. Since in new focus of cutaneous leishmaniasis, the majority of cases occur among children, continuous monitoring of epidemiological aspects of $\mathrm{CL}$ is necessary for proper decisions about effective interventions to control and manage leishmaniosis among this susceptible group. Therefore, this study is designed to determine the epidemiology and factors associated with the prevalence of cutaneous leishmaniasis among children during the 2016-2020 years in Hormozgan provinces as one of the most critical CL foci in the southeast of Iran.

\section{Materials and Methods}

This descriptive study was conducted in Hormozgan province from 2016 to 2020. In this study, demographic and clinical features of all pediatric (0-15 years old) cutaneous leishmaniasis patients $(\mathrm{PCL})$ referred to the regional health centers for PCL treatment and follow-up were recorded. All suspicious PCL patients referred to the health centers were examined, and parasitological verifications were used to diagnose the PCL. After the examination, data of all microscopic approved cases were recorded in epidemiological registration forms. In addition, all new cases of PCL registered in the disease surveillance system of Hormozgan University of Medical Sciences were recorded. Data of patients included demographic characteristics, such as place of residence (urban or rural) and sex, as well as clinical information, including the number and location of the wounds.

Children and their parents received an adequate and understandable explanation about the procedures and objectives of the study. Also, they were informed that their participation is voluntary and they can withdraw from the study at any time; then, they signed the informed consent form. Besides, the data were collected anonymously by using identification numbers instead of participant names, and collected data were kept confidential. This study was confirmed by the Ethical Committee of Hormozgan University of Medical Sciences (Ethics Committee Code: IR.HUMS.REC.1398.251).

Descriptive statistics were used to show relative frequencies, averages, and percentages. Further, the chi-square and t-test were used to analyze the data. Data analysis was performed using SPSS ver.21 software. 


\section{Results}

During the study period, a total of 394 laboratoryconfirmed cases of pediatric cutaneous leishmaniasis (PCL) were recorded in Hormozgan province. The highest and lowest frequencies of PCL were found to be 106 (26.9\%) in 2017 and 47 (11.9\%) in 2020 (Table 1).

Table 1. Frequency of PCL in terms of age group, sex, and place of residence in Hormozgan province, southeast Iran, 2016-2020

\begin{tabular}{|c|c|c|c|c|c|c|c|c|c|c|c|c|c|c|c|c|}
\hline \multirow{4}{*}{ Years } & \multicolumn{14}{|c|}{ Variable } & \multirow{3}{*}{\multicolumn{2}{|c|}{ Total }} \\
\hline & \multicolumn{4}{|c|}{ Sex } & \multicolumn{6}{|c|}{ Age groups } & \multicolumn{4}{|c|}{ Place of residence } & & \\
\hline & \multicolumn{2}{|c|}{ Male } & \multicolumn{2}{|c|}{ Female } & \multicolumn{2}{|c|}{$0-5$} & \multicolumn{2}{|c|}{$6-10$} & \multicolumn{2}{|c|}{$11-15$} & \multicolumn{2}{|c|}{ Rural } & \multicolumn{2}{|c|}{ Urban } & & \\
\hline & No. & $\%$ & No. & $\%$ & No. & $\%$ & No. & $\%$ & No. & $\%$ & No. & $\%$ & No. & $\%$ & No. & $\%$ \\
\hline 2016 & 23 & 45.1 & 28 & 54.9 & 37 & 72.5 & 11 & 21.6 & 3 & 5.9 & 31 & 60.8 & 20 & 39.2 & 51 & 12.9 \\
\hline 2017 & 55 & 51.9 & 51 & 48.1 & 69 & 65.1 & 32 & 30.2 & 5 & 4.7 & 68 & 64.2 & 38 & 35.8 & 106 & 26.9 \\
\hline 2018 & 58 & 58.0 & 42 & 42.0 & 55 & 55.0 & 37 & 37.0 & 8 & 8.0 & 75 & 75.0 & 25 & 25.0 & 100 & 26.4 \\
\hline 2019 & 45 & 50.0 & 45 & 50.0 & 54 & 60.0 & 30 & 33.3 & 6 & 6.7 & 67 & 74.4 & 23 & 25.6 & 90 & 22.9 \\
\hline 2020 & 23 & 48.9 & 24 & 51.1 & 24 & 51.1 & 15 & 31.9 & 8 & 17.0 & 23 & 48.9 & 24 & 41.1 & 47 & 11.9 \\
\hline Total & 204 & 51.8 & 190 & 48.2 & 239 & 60.7 & 125 & 31.7 & 30 & 7.6 & 264 & 67.0 & 130 & 33.0 & 394 & 100 \\
\hline
\end{tabular}

During these years, the PCL incidence also showed a declining trend from 10.37 to 7.85 per 100,000 people in the study population (Fig. 1).

The highest frequency of PCL was recorded in Hajiabad with 160 (40.5\%), followed by Bastak with 125(31.6\%) and Bandar Abbas with 66 $(16.8 \%)$ cases. Rudan and Sirik counties had the least number of PCL with $2(0.5 \%)$ and $1(0.3 \%)$ cases, respectively (Table 2 ). The number of PCL cases in different counties is shown in Fig. 2.

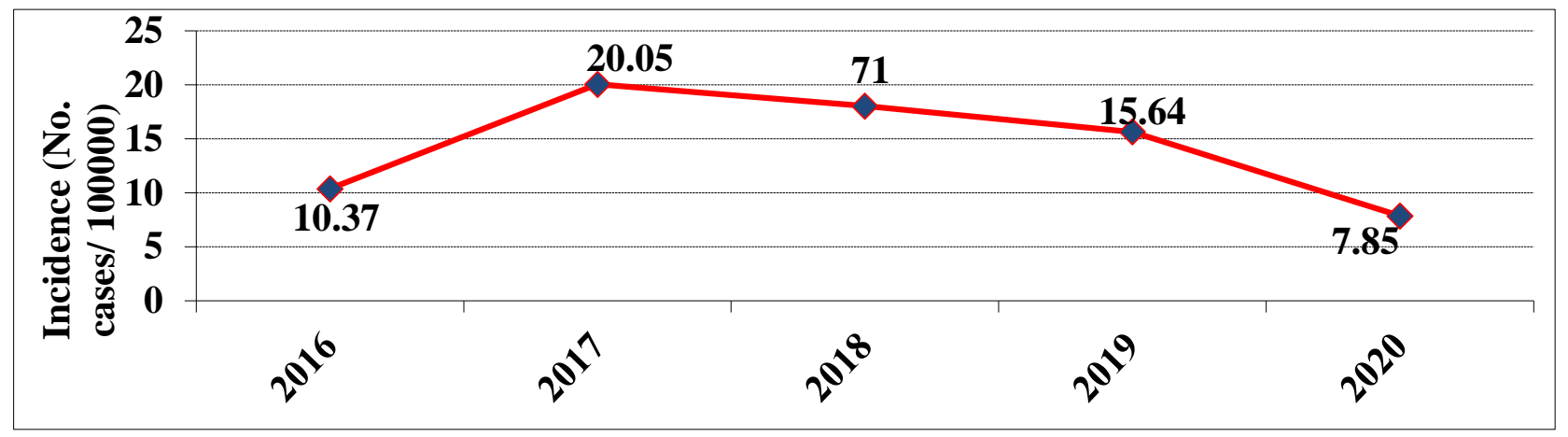

Fig. 1. Incidence of PCL in Hormozgan province, southeast Iran, 2016-2020

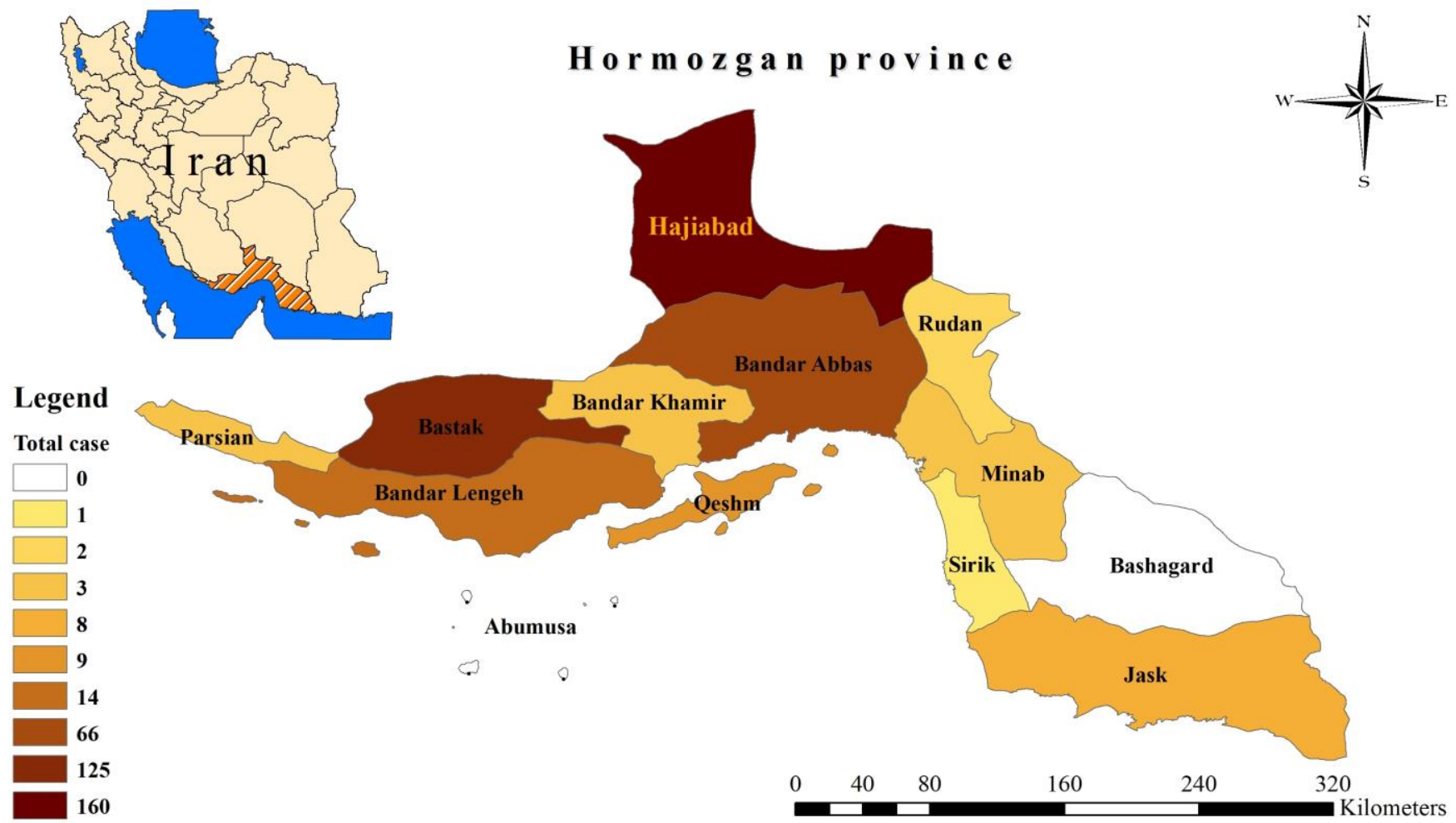

Fig. 2. Map of Hormozgan province with the distribution of PCL cases in different counties during 2016-2020 
Table 2. Frequency of PCL in different counties of Hormozgan province, southeast Iran, 2016-2020

\begin{tabular}{ccc}
\hline \multirow{2}{*}{ County } & \multicolumn{2}{c}{ Notal case } \\
\cline { 2 - 3 } & No. & $\%$ \\
\hline Hajiabad & 160 & 40.5 \\
\hline Bastak & 125 & 31.6 \\
\hline Bandar Abbas & 66 & 16.8 \\
\hline Bandar Lengeh & 14 & 3.6 \\
\hline Qeshm & 9 & 2.3 \\
\hline Jask & 8 & 2.0 \\
\hline Khamir & 3 & 0.8 \\
\hline Parsian & 3 & 0.8 \\
\hline Minab & 3 & 0.8 \\
\hline Rudan & 2 & 0.5 \\
\hline Sirik, & 1 & 0.3 \\
\hline Total & 394 & 100
\end{tabular}

The average age of patients was $5.2 \pm 3.8$ years, ranging from 1 to 15 years. The highest and least number of PCL occurred in children in the 0-5- and 11-15-years old age groups, respectively (Table 1 ). Out of 394 PCL cases, 204 (51.8\%) were male, while 190 (48.2\%) were female (Table 1$)$.

According to the results, 264 of the PCL cases $(67 \%)$ occurred in rural areas, and the rest in urban areas (Table 1). The difference between sex and residential area of the patients was observed to be statistically significant in terms of the prevalence of the disease $(p=0.021,95 \% \mathrm{Cl}$ 0.001-0.041).

As seen in Table 3, most lesions were mainly observed on the face $(208 / 394 ; 52.7 \%)$ and hands $(81 / 394 ; 20.6 \%)$. According to the chi-square test, a significant relationship was found between sex and lesion place $(p=0.042)$, so that the frequency of lesions in exposed areas of the body, including trunk, feet, and hands, was lower in females.

Clinical features indicated that most infected children had a single lesion (271/394; 68.8\%). Double lesions were observed in 75 (19\%) of cases, and $48(12.2 \%)$ of patients had multiple lesions (Table 3 ). The highest number of lesions observed was found to be 9 per person, and the average was 1.5 per person.

Table 3. The clinical features of PCL in Hormozgan province, southeast Iran, 2016-2020

\begin{tabular}{|c|c|c|c|c|c|c|c|c|c|c|c|c|c|c|c|c|}
\hline \multirow{4}{*}{ Years } & \multicolumn{16}{|c|}{ Variable } \\
\hline & \multicolumn{8}{|c|}{ Location of the lesion } & \multicolumn{8}{|c|}{ Number of lesions } \\
\hline & \multicolumn{2}{|c|}{ Face } & \multicolumn{2}{|c|}{ Hands } & \multicolumn{2}{|c|}{ Feet } & \multicolumn{2}{|c|}{ Other } & \multicolumn{2}{|c|}{$\overline{1}$} & \multicolumn{2}{|c|}{2} & \multicolumn{2}{|c|}{3} & \multicolumn{2}{|c|}{$\geq 4$} \\
\hline & No. & $\%$ & No. & $\%$ & No. & $\%$ & No. & $\%$ & No. & $\%$ & No. & $\%$ & No. & $\%$ & No. & $\%$ \\
\hline 2016 & 33 & 64.7 & 6 & 11.8 & 3 & 5.9 & 9 & $\overline{17.6}$ & 29 & 56.9 & 13 & 25.5 & 5 & 9.8 & 4 & 7.8 \\
\hline 2017 & 60 & 56.6 & 25 & 23.6 & 9 & 8.5 & 12 & 11.3 & 67 & 63.2 & 24 & 22.6 & 11 & 10.4 & 4 & 3.8 \\
\hline 2018 & 55 & 55.0 & 20 & 20.0 & 8 & 8.0 & 17 & 17.0 & 73 & 73.0 & 18 & 18.0 & 4 & 4.0 & 5 & 5.0 \\
\hline 2019 & 36 & 40.0 & 23 & 25.6 & 8 & 8.9 & 23 & 25.6 & 65 & 72.1 & 14 & 15.6 & 6 & 6.7 & 5 & 5.6 \\
\hline 2020 & 24 & 51.1 & 7 & 14.9 & 3 & 6.4 & 13 & 27.6 & 37 & 78.6 & 6 & 12.8 & 2 & 4.3 & 2 & 4.3 \\
\hline Total & 208 & 52.7 & 81 & 20.6 & 31 & 7.9 & 74 & 18.8 & 271 & 68.8 & 75 & 19.0 & 28 & 7.1 & 20 & 5.1 \\
\hline
\end{tabular}

Seasonal distribution of PCL in Hormozgan province showed a higher frequency of cutaneous leishmania cases in winter and fall with $183(46.5 \%)$ and $78(19.8 \%)$ cases, respectively (Fig. 3).
A statistically significant association was found between the prevalence of the disease and the season of its occurrence $(p=0.001,95 \% \mathrm{Cl} 0.000$ 0.002).

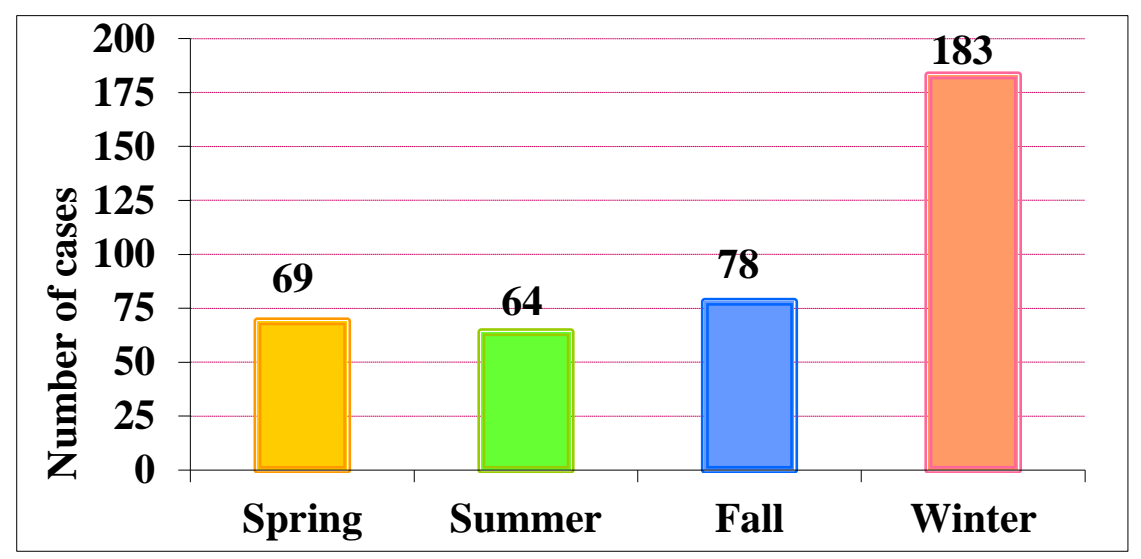

Fig. 3. Seasonal distribution of PCL in Hormozgan province, southeast Iran, 2016-2020 


\section{Discussion}

Hormozgan province is considered one of the important CL foci in the southeastern part of Iran. Once the malaria elimination program was initiated, the application of insecticides was decreased, and its use was restricted to some areas of Iran. In this regard, due to less restriction of insecticide usage in some regions, the incidence of $\mathrm{CL}$ increased notably, and the condition of the disease was changed to the epidemic in some counties of the province. Different researches have been conducted to study the epidemiological status of CL in three main foci, including Jask, Hajiabad, and Bandar Abbas [19, 21, 22, 23]. According to the results, children are the most infected group in this province (as seen in other endemic foci of the $C L$ throughout the country), with most cases commonly occurring in 0-4- and 59 -years old groups [24, 25].

According to the results of this study, the frequency of $\mathrm{PCL}$ cases has decreased from $10.37 / 100000$ in 2016 to $7.85 / 100000$ in 2020 . The main reason for this decrease may be related to an increase in active case detection and awareness of PCL. In addition, climatic change and consecutive drought have significantly contributed to reducing the frequency of cases.

In this study, most of the PCL cases were males. This finding is in agreement with that of other studies in Iran that have shown a higher incidence rate of the disease in men $[5,26]$. Parallel findings have been reported from Turkey, India, and Pakistan $[6,7,27]$. This difference in the risk of PCL infection between males and females may be due to the differences in sex roles but not sex characteristics [28]. In this regard, the presence of men outside the home, as well as their type of clothing and social activities, increases their exposure to infective sand fly vectors [29].

In this study, the highest number of PCL cases was observed in the age groups of 0-5 years old.

This finding is in line with that of other studies in PCL endemic areas of Iran, including Golestan, Kerman, and Fars provinces [26, 29,30]. Further, this study is supported by other studies in India, Turkey, and Pakistan that indicated PCL being more prevalent in younger age groups [6, 7, 27]. Contrary to the results of these studies, a study in Iran showed that the highest number of leishmaniasis cases were among the age group of 20-29 years old, while the lowest number was in the age groups of $0-9$ years $[12,31]$. The main explanation for a higher prevalence of leishmaniasis in younger age groups is that children possibly maintain personal hygiene less than adults and thus are more vulnerable; also, these age groups are non-immune populations exposed to the infective bite of the sand flies for the first time in their life.

The result of this study also indicated that the lesions were mostly found on the face and hands. This finding is similar to the distribution pattern of the $\mathrm{CL}$ lesions reported from different $\mathrm{CL}$ endemic areas of Iran [12, 13, 32-34]. The reason for this may be the short proboscis of sand flies, making them incapable of biting through clothing; therefore, they bite exposed parts of the body, including feet, hands, and face.

According to the results of this study, the highest prevalence of the disease was in the winter and fall. This finding is in agreement with previous studies conducted in Iran, revealing a high prevalence of $\mathrm{CL}$ in the winter and fall seasons [33-36]. The seasonal trend of CL is associated with the known vector activity. There is a lag time between developing skin lesions and referring the infected subjects to the physicians. This lag time demonstrates the time intervals between the peak activity of the sand fly in the spring and summer and the peak of the prevalence of leishmania in the autumn and winter [37].

The current study showed that the highest prevalence of the PCL occurred in the rural areas, similar to the previous studies conducted in this province $[19,21,22,24]$. The prevalence of $P C L$ in the rural regions of Hormozgan province shows the endemicity of the disease in this area. In this regard, it seems that dumping the garbage and construction wastes around the residential areas and developing agricultural projects have resulted in the attraction of sand flies and rodents as reservoir hosts near the villages.

\section{Conclusion}

The results indicate that $\mathrm{PCL}$ is endemic in Hormozgan provinces, with more prevalence in children. Appropriate educational interventions for prevention along with the active surveillance for rapid detection and treatment of the patients should be considered to reduce the prevalence of $\mathrm{PCL}$ in this province.

\section{Acknowledgement}

The authors of this article are grateful for the support of the director and the staff of regional health centers of the Hormozgan province, who cooperated and participated in this study.

Conflict of interest: None declared. 


\section{References}

1. Steverding D. The history of leishmaniasis. Parasit Vectors 2017; 10(1):82.

2. Akhoundi M, Kuhls $K$, Cannet A, Votýpka J, Marty $P$, Delaunay $P$, et al. A Historical Overview of the Classification, Evolution, and Dispersion of Leishmania Parasites and Sandflies. PLoS Negl Trop Dis 2016; 10(3):e0004349.

3. Alvar J, Vélez ID, Bern C, Herrero M, Desjeux $\mathrm{P}$, Cano J, et al. Leishmaniasis worldwide and global estimates of its incidence. PloS One 2012; 7(5):e35671.

4. World Health Organization. Leishmaniasis. Geneva, Switzerland: World Health Organization; 2020.

5. Talari SA, Talaei R, Shajari G, Vakili Z, Taghaviardakani A. Childhood cutaneous leishmaniasis: report of 117 cases from Iran. Korean J Parasitol 2006; 44(4):355-60.

6. Aksoy M, Doni N, Ozkul HU, Yesilova Y, Ardic $\mathrm{N}$, Yesilova $A$, et al. Pediatric Cutaneous Leishmaniasis in an Endemic Region in Turkey: A Retrospective Analysis of 8786 Cases during 1998-2014. PLoS Negl Trop Dis 2016; 10(7):e0004835.

7. Agrawal S, Khandelwal K, Bumb RA, Oghumu $S$, Salotra P, Satoskar AR. Pediatric cutaneous leishmaniasis in an endemic region in India. Am J Trop Med Hyg 2014; 91(5):901-4.

8. Fenniche $S$, Souissi A, Benmously $R$, Ben Jannet S, Marrak H, Mokhtar I. [Childhood cutaneous leishmaniasis in Tunisia: retrospective study of 60 cases]. Med Trop (Mars) 2006; 66(5):456-60.

9. Qasmi S, Elguelbazouri N, Belgnaoui FZ, Marcil $\mathrm{T}$, Bouhllab J, Senouci K, et al. Childhood cutaneous leishmaniasis: Experience of a Moroccan unit of dermatology. Dermatol Online J 2008; 14(12):18.

10. Ghatee MA, Taylor WR, Karamian M. The Geographical Distribution of Cutaneous Leishmaniasis Causative Agents in Iran and Its Neighboring Countries, A Review. Front Public Health 2020; 8:11.

11. Karimi A, Hanafi-Bojd AA, Yaghoobi-Ershadi MR, Akhavan AA, Ghezelbash Z. Spatial and temporal distributions of phlebotomine sand flies (Diptera: Psychodidae), vectors of leishmaniasis, in Iran. Acta Trop 2014; 132:1319.

12. Khazaei S, Mohammadian Hafshejani A, Saatchi M, Salehiniya $H$, Nematollahi S. Epidemiological Aspects of Cutaneous Leishmaniasis in Iran. Arch Clin Infect Dis 2015; 10(3):e28511.

13. Norouzinezhad F, Ghaffari F, Norouzinejad A, Kaveh F, Gouya MM. Cutaneous leishmaniasis in Iran: Results from an epidemiological study in urban and rural provinces. Asian Pac J Trop Biomed 2016; 6(7):614-9.

14. Yaghoobi-Ershadi M. Phlebotomine Sand Flies (Diptera: Psychodidae) in Iran and their Role on
Leishmania Transmission. J Arthropod Borne Dis 2012; 6(1):1-17.

15. Sofizadeh A, Hanafi-Bojd AA, Shoraka HR. Modeling spatial distribution of Rhombomys opimus as the main reservoir host of zoonotic cutaneous leishmaniasis in northeastern Iran. J Vector Borne Dis 2018; 55(4):297-304.

16. Sofizadeh A, Rassi $Y$, Hanafi-Bojd AA, Shoraka HR, Mesgarian F, Rafizadeh S. Distribution and ecological aspects of sand flies (Diptera: Psychodidae) species in Northeastern Iran. Asian Pac J Trop Med 2018; 11(9):526-33.

17. Oryan A, Akbari M. Worldwide risk factors in leishmaniasis. Asian Pac J Trop Med 2016; 9(10):925-32.

18. Desjeux $P$. The increase in risk factors for leishmaniasis worldwide. Trans $\mathrm{R}$ Soc Trop Med Hyg 2001; 95(3):239-43.

19. Zare S, Baghestani S. Cutaneous leishmaniasis in Hormozgan, Iran. Int J Dermatol 2001; 40(10):629-31.

20. Hanafi-Bojd AA, Khoobdel M, SoleimaniAhmadi M, Azizi K, Aghaei Afshar A, Jaberhashemi SA, et al. Species Composition of Sand Flies (Diptera: Psychodidae) and Modeling the Spatial Distribution of Main Vectors of Cutaneous Leishmaniasis in Hormozgan Province, Southern Iran. J Med Entomol 2018; 55(2):292-9.

21. Fekri S, Hanafi-Bojd AA, Salari Y, Davoodian $P$, Safari $\mathrm{R}$, Dadvand $\mathrm{H}$, et al. Situational Analysis of Cutaneous Leishmaniasis in an Endemic Focus of the Disease, Southeastern Iran. J Arthropod Borne Dis 2018; 12(1):76-84.

22. Azizi K, Moemenbellah-Fard MD, Fakoorziba MR, Fekri S. Gerbillus nanus (Rodentia: Muridae): a new reservoir host of Leishmania major. Ann Trop Med Parasitol 2011; 105(6):431-7.

23. Sanei-Dehkordi A, Soleimani-Ahmadi M, Zare $M$, Mirzaei H. Epidemiological features of cutaneous leishmaniasis and distribution of sand flies in an endemic area in southeast of Iran. Parasite Epidemiol Control 2021; 14:e00220.

24. Shirzadi MR, Esfahani SB, Mohebali M, Yaghoobi-Ershadi MR, Gharachorlo F, Razavia $M R$, et al. Epidemiological status of leishmaniasis in the Islamic Republic of Iran, 1983-2012. East Mediterr Health J 2015; 21(10):736-42.

25. Karami M, Doudi M, Setorki M. Assessing epidemiology of cutaneous leishmaniasis in Isfahan, Iran. J Vector Borne Dis 2013; 50(1):30-7.

26. Jorjani O, Kamalinia HR, Mehrbakhsh Z, ZiaeiHezarjaribi H, Pourrostami K, Mansourian M, et al. Pediatric Cutaneous Leishmaniasis in Golestan Province, Iran: A Cross-Sectional Study of 8-years. Int J Pediatr 2019; 7(8):98319.

27. Bari AU. Childhood Cutaneous Leishmaniasis. J Clin Diagn Res 2008; 2(4):973-8. 
28. Khademvatan S, Salmanzadeh S, ForoutanRad M, Bigdeli S, Hedayati-Rad F, Saki J, et al. Spatial distribution and epidemiological features of cutaneous leishmaniasis in southwest of Iran. Alex J Med 2017; 53(1):93-8.

29. Khosravi A, Sharifi I, Dortaj E, Aghaei Afshar A, Mostafavi M. The present status of cutaneous leishmaniasis in a recently emerged focus in south-west of Kerman Province, Iran. Iran J Public Health 2013; 42(2):182-7.

30. Bazrafshan MR, Shokrpour N, Delam H. TenYear Trends of the Incidence of Cutaneous Leishmaniasis in the South of Fars Province, Iran, During 2007-2016. Int J Epidemiol Res 2020; 7(3):120-4.

31. Akhlagh A, Salehzadeh A, Zahirnia AH, Davari B. 10-Year Trends in Epidemiology, Diagnosis, and Treatment of Cutaneous Leishmaniasis in Hamadan Province, West of Iran (2007-2016). Front Public Health 2019; 7:27.

32. Nateghi Rostami M, Saghafipour A, Vesali E. A newly emerged cutaneous leishmaniasis focus in central Iran. Int J Infect Dis 2013; 17(12):e1198-206.

33. Razmjou S, Hejazy H, Motazedian MH, Baghaei
M, Emamy M, Kalantary M. A new focus of zoonotic cutaneous leishmaniasis in Shiraz, Iran. Trans R Soc Trop Med Hyg 2009; 103(7):727-30.

34. Rezaee N, Raissi V, Rajaeipour A, Nazari M, Getso M, Taghipour A, et al. Epidemiology, Associated Factors and Treatment Methods of Cutaneous Leishmaniasis Based on Previous Data from 2013 to 2018 in Ilam, Western Iran. Acta Parasitol 2020; 65(3):760-7.

35. Mohammadi J, Soltani A. Epidemiologic Profile of Cutaneous Leishmaniasis between 20102016 in an Endemic Area of Fars Province, South Iran. Shiraz E Med J 2019; 20(9):e86445.

36. Rahmanian V, Rahmanian $\mathrm{K}$, Sarikhani $\mathrm{Y}$, Sotoodeh Jahromi A, Madani A. Epidemiology of Cutaneous Leishmaniasis, West South of Iran, 2006-2014. J Res Med Dent Sci 2018; 6(2):378-83.

37. Al-Tawfiq JA, AbuKhamsin A. Cutaneous leishmaniasis: a 46-year study of the epidemiology and clinical features in Saudi Arabia (1956-2002). Int J Infect Dis 2004; 8(4):244-50. 